\title{
Educação física cultural e africanidades: exu, saberes discentes e encruzilhadas
}

\author{
Cultural physical education and africanities: exu, student knowledge and \\ crossroads
}

\author{
Ronaldo dos Reis \\ Mestre em Educação \\ Universidade de São Paulo - USP \\ São Paulo, SP - Brasil. \\ ronaldosonyc@usp.br \\ Marcos Garcia Neira \\ Doutor em Educação \\ Universidade de São Paulo - USP. \\ São Paulo, SP - Brasil. \\ mgneira@usp.br
}

\begin{abstract}
Resumo: A presente pesquisa teve como objetivo compreender como as/os estudantes significam as práticas corporais de matriz afro-brasileira abordadas nas aulas de Educação Física culturalmente orientadas. O trabalho de campo consistiu na tematização de danças de matrizes culturais afro-brasileiras, ao longo de dois anos letivos, com turmas do $8^{\circ}$ e $9^{\circ}$ ano do Ensino Fundamental em uma escola pública. Os dados produzidos foram submetidos à análise cultural, fazendo emergir encruzilhadas, mobilizadas no entrecruzamento dos pressupostos do currículo cultural de Educação Física, estudos decoloniais e pedagogia das encruzilhadas. Com base no pensamento de fronteira, materializado na rejeição de uma maneira única de ler a realidade, na desobediência epistêmica, anunciada por uma perspectiva pluriversal, constatada nas performatividades das/os estudantes, além de evidenciadas em cruzos, rolês e ebós epistemológicos, foi possível a aspiração de uma epistemologia exuística, observada na ressignificação das gestualidades, nas vivências organizadas, que emergiram nas frestas, transgressões, rasuras, devires, incertezas, mobilidades, rebeldias, síncopes. Isso fez surgir possibilidades de vir a ser e de existir, podendo abrir outros caminhos e novas encruzilhadas.
\end{abstract}

Palavras chave: africanidades; currículo cultural; encruzilhadas.

Abstract: This research aimed to understand how students mean the body practices of Afro-Brazilian matrix addressed in culturally oriented Physical Education classes. The fieldwork consisted of thematization of dances from Afro-Brazilian cultural matrices over two academic years with classes from two last years of elementary school in a public school. The data produced were subjected to cultural analysis, causing crossroads to emerge, mobilized in the intersection of the assumptions of the cultural curriculum of Physical Education, decolonial studies and pedagogy of crossroads. Based on frontier thinking materialized in the rejection of a unique way of reading reality, in epistemic disobedience, announced by a pluriversal perspective found in the performativities of students, evidenced in epistemological crosses, rollers and ebós, which enables the aspiration of an exuistic epistemology observed in the resignification of gestures, in organized experiences, emerging in the cracks, transgressions, erasures, becomings, uncertainties, mobilities, rebellions, syncopations, giving rise to possibilities of becoming and existing, opening up other paths and new crossroads.

Key-words: africanities; cultural curriculum; crossroads.

Cite como

(ABNT NBR 6023:2018)

REIS, Ronaldo dos; NEIRA, Marcos Garcia. Educação física cultural e africanidades: exu, saberes discentes e encruzilhadas. Dialogia, São Paulo, n. 38, p. 1-14, e20456, maio/ago. 2021. Disponível em:https://doi.org/10.5585/38.2021.20456.

American Psychological Association (APA)

Reis, R. dos., \& Neira, M. G. (2021, maio/ago.). Educação física cultural e africanidades: exu, saberes discentes e encruzilhadas. Dialogia, São Paulo, 38, p. 1-14, e20456. https://doi.org/10.5585/38.2021.20456. 


\section{Introdução}

Inspirado nas teorias pós-críticas, o currículo cultural de Educação Física tem como objetivo formar para a leitura da ocorrência social das práticas corporais e sua reelaboração, conforme o contexto, almejando a formação de sujeitos solidários. Professoras e professores, ao colocarem em ação a proposta, tematizam brincadeiras, danças, lutas, ginásticas e esportes, entendidos como temas culturais, com o intuito de analisar suas representações e significados mediante problematizações que emergem durante as vivências.

Os incômodos, identificados na atuação profissional, somados ao agenciamento pelos princípios ético-políticos do currículo cultural de Educação Física, propiciaram outras formas de pensar as práticas escolares, bem como outros olhares sobre a presença da população negra na sociedade, que, vez por outra, está enviesada por uma visão estereotipada da/o negra/o escravizada/o pelo europeu. No contexto da pesquisa, debruçamo-nos nas africanidades presentes nas danças mapeadas, o que orientou as situações didáticas junto às turmas de $8^{\circ}$ e $9^{\circ}$ ano do Ensino Fundamental, em busca de respostas às seguintes questões: como as/os estudantes percebem a presença/ausência de determinadas práticas corporais no currículo? Como percebem (se percebem) a recorrência de algumas práticas corporais em detrimento de outras? Como as/os estudantes inicialmente significam as práticas corporais ao se depararem com a discussão das relações étnico-raciais nas aulas de Educação Física? Quais seriam os efeitos da problematização dos significados atribuídos às manifestações e às pessoas que delas participam?

Uma vez que a Educação Física culturalmente orientada se apresenta como alternativa contra-hegemônica e antifascista (no contexto desta pesquisa, também, se apresentando antirracista), pois assume para si o compromisso de afirmar as diferenças (NEIRA, 2020), elegemos por objetivo compreender como as/os estudantes significam as práticas corporais de matriz afrobrasileira. Para tanto, consideramos o entendimento de Hall (2016), para quem a linguagem é um produto social, no qual os significados são produzidos por meio dos sistemas de representação.

Os trabalhos de Santos Júnior (2020), Martins (2019), Oliveira Junior (2017), Araújo e Neira (2014), Neira (2016a) e Neves (2018) também se detiveram sobre o processo de significação dos estudantes, entretanto, fizeram-no de modo amplo, sem atentar especificamente aos efeitos gerados pela tematização de práticas corporais de matriz afro-brasileira, o que singulariza nosso objeto de estudo. 


\section{Metodologia}

A presente pesquisa foi realizada no contexto de nossa prática docente, uma vez que, ao nos posicionarmos como professor e pesquisador, tivemos, como campo, o cotidiano das aulas de Educação Física, desenvolvidas em 2018 e 2019, em uma escola pública na Zona Oeste da cidade de São Paulo, na qual a proposta educacional é comprometida com os direitos humanos, a igualdade, o reconhecimento, a valorização das diferenças e da diversidade, a democracia e a formação para a cidadania. O projeto político pedagógico adota princípios orientados para diálogo, respeito e solidariedade, nos quais as/os professoras/es sustentam suas práticas pedagógicas.

Ao colocar em ação o currículo cultural da Educação Física, sabidamente inspirado nas chamadas teorias pós-críticas, em que o docente é agenciado por princípios ético-políticos e promove encaminhamentos pedagógicos (NEIRA, 2019), foram utilizadas diferentes formas de registro, como fotos, vídeos e transcrições das falas dos estudantes no caderno do professor, em que constam os objetivos das aulas e as atividades de ensino propostas.

A documentação das expressões dos estudantes é um traço característico do currículo cultural de Educação Física, apresentado como elemento que, após análise, possibilita repensar as situações didáticas vindouras, propiciando prosseguimento à tematização da prática corporal, foco dos trabalhos naquele período letivo. Müller (2016) aponta que o registro, para além de subsidiar a continuidade das ações, permite revisitar e refletir sobre o próprio processo formativo.

Ao nos distanciarmos efetivamente de perspectivas teórico-metodológicas que reforçam pressupostos arraigados numa lógica positivista, a qual intenciona uma resposta concreta, única ou interpretações que universalizam os conhecimentos, os materiais produzidos, durante o trabalho de campo, foram submetidos à análise cultural, uma vez que essa forma de interpretação nos possibilita ir além do que é visível. Ademais, viabiliza uma saída estratégica na descrição de uma realidade objetiva, construindo, assim, uma possível leitura do contexto social (WORTMANN, 2002; MORAES, 2015; LISBOA FILHO; MACHADO, 2015).

Segundo Moraes (2015), o/a pesquisador/a se envolve em um ambiente interpretativo e, no ir e vir da pesquisa, supera descrições superficiais de fatos descontextualizados, o que viabiliza leituras e análises mais densas dos textos culturais marcados pelos contextos de sua produção. Wortmann (2002) recomenda a "penetração nas linguagens" e o "garimpo" dos significados na multiplicidade dos textos produzidos. As análises culturais utilizam-se de inúmeros campos teóricos e metodológicos, assumindo abertamente um caráter parcial, incompleto e contextual. Paraíso (2014) complementa ao indicar que as pesquisas pós-críticas experimentam, inspiram, desmontam, juntam, articulam, multiplicam, produzem, atribuem novos significados, artistam, 
inventam, criam olhares. Segundo Reis (2021), a análise cultural movimenta-se, como o capoeirista, que busca encontrar os espaços vazios, as frestas, no ir e vir da ginga, de um lado para o outro, muitas vezes, ficando de cabeça para baixo para poder ver melhor o espaço que tentará ocupar, no simples descuido do seu oponente.

Realizar uma análise cultural implica partir da compreensão do todo que envolve a pesquisa de uma prática social, para examinar as significações e valores implícitos e explícitos em um certo modo de vida (COSTA, 2000). Isso permite aventar aproximações com o pensamento de fronteira (MIGNOLO, 2013), considerar a metáfora da capoeira (NEIRA, 2007) e o rolê epistemológico que emerge das traquinagens como atos de antidisciplina e de rasura aos imprevistos coloniais. Essa ação configura um fazer nas encruzilhadas, potencializa o movimento e as transformações, confrontando as noções desencantadas dos modelos monorraciais e universalistas. Contribui, assim, para uma perspectiva pluriversal, rompendo com o sujeito uno, para demandar a desobediência epistêmica (MIGNOLO, 2008).

\section{Análise dos dados}

As significações e efeitos da prática pedagógica limitam-se ao que foi possível ver, ouvir e à nossa interpretação; mesmo que tenhamos produzido uma quantidade expressiva de registros das aulas, temos ciência de que muitos detalhes se perderam. Diante disso, o que segue é uma das possibilidades alcançadas por nossas significações, totalmente parciais e à mercê da docência efetivada.

Assentamos as análises principalmente nos cruzos entre as produções decoloniais (MIGNOLO, 2008, 2013; QUIJANO, 2005) com a pedagogia das encruzilhadas, pela qual acessamos os princípios de uma epistemologia exuística. Rufino (2019) anuncia uma pedagogia baseada nas encruzilhadas como campo das possibilidades, disponível a novos rumos, com práticas inventivas numa perspectiva transgressiva.

A figura de Exu, que mobilizamos em algumas de nossas análises, nada tem de relação com a associação pejorativa ao diabo cristão, visto como amoral, relegado ao substantivo do pecado, do descontrole e do perigo, interditado pela lógica colonial, mas sim com uma proposta de resistência, de conhecimentos relegados pela colonialidade, baseados nas africanidades, principalmente dos povos iorubas, como forma de descolonização dos saberes. Assim, entendemos que: 
[...] manter Exu, princípio explicativo de mundo, sobre o aprisionamento da condição de diabo cristão favoreceu/favorece o projeto colonial na face da redenção cristã (bem versus mal) e o racionalismo ocidental por via da dominação de outros conhecimentos, devemos cismar essa lógica ou como dizem por aí 'aqui ninguém é santo'. (SIMAS; RUFINO, 2019 , p.50).

Segundo Rufino (2019), ao transfigurar Exu em demônio cristão, o colonialismo cometeu uma grande tragédia, reduzindo a complexidade das culturas negro-africanas, seus modos de vida, visões de mundo, princípios explicativos e saberes necessários para a formação de uma sociedade orientada pela diversidade como princípio ético.

Exu, anunciado como o diabo, é totalmente simplificado. Acaba sendo fixado entre os binarismos que só interessam a uma perspectiva de sujeito universal, idealizado por uma obsessão dicotômica e cartesiana de ser. O pensamento colonial utiliza essa artimanha para anular toda a potência de vida existente em Exu, incontrolável, indisciplinável, negociada nas esquivas, golpes, frestas e seduções. A pedagogia exuística borra as fronteiras entre o certo ou errado, bem ou mal, desvio ou regra, anunciando os caminhos como possibilidades.

\section{Primeira esquina: o pensamento de fronteira}

$\mathrm{Na}$ primeira esquina, anunciamos os significados produzidos, de maneira provisória e adiados, uma vez que as danças que emergiram do mapeamento se apresentaram como possibilidades de vivência durante a tematização. No currículo cultural da Educação Física, a vivência pode ser a:

[...] expressão da gestualidade a partir das referências que os estudantes possuem. Seria contraditório um "ensinar a fazer". O foco reside muito mais no fazer como já fez ou como se acha que deve fazer. É esse brincar, dançar, lutar, praticar o esporte ou ginástica descompromissados com o pensar sobre que potencializa a dimensão estética, o sentir na pele. (NEIRA, 2019, p. 63).

A análise das falas das/os estudantes propicia o entendimento de que os significados se apresentaram, inicialmente, por meio da forma como foram acessados e, assim, integraram práticas do cotidiano; ou, como alerta Hall (2006), os significados culturais não estão na cabeça, têm efeitos reais e regulam práticas sociais. Ao produzirem vivências e gestualidades a partir da referência dos vídeos e imagens a que tiveram acesso, é possível verificar a elaboração de outros significados, mesmo que recheados de estranhamentos.

Ao performarem as danças após assistirem ao musical West side stories, as/os estudantes recriaram cenas com socos, giros, saltos, "voadoras", rolando no chão ou se batendo para representar um confronto entre gangues. À medida que as vivências se concretizaram como 
possibilidades, cada um/a ou cada grupo, à sua maneira, dançou, observou, sugeriu músicas e passos, abrindo caminhos que potencializaram a dança tematizada.

As vivências, durante as aulas, permitiram às/aos estudantes inventar, fazendo emergir fronteiras, zonas fronteiriças, frestas, ocupando os lugares de vazio com outras possibilidades com base nos corpos, sons e palavras, das quais eclodiram a reivindicação por Exu, seus princípios e a encruzilhada.

Ao lermos as performatividades no samba-rock, observamos atuações na fronteira (MIGNOLO, 2008). O pensamento fronteiriço ajuda a explicar as razões de as performatividades das/os estudantes terem rejeitado uma única forma de ler a prática corporal, ao mesmo tempo em que enunciaram e reproduziram o discurso hegemônico, o que demonstra que alguns significados escapam a qualquer controle. Basta prestar atenção às narrativas apaziguadoras, visões românticas e folclorizadas sobre os processos diaspóricos aos quais a população negra africana foi submetida.

Que a maioria desses diferentes tipos de danças são bem iguais entre si, apesar das diferenças, da impressão que todos eles foram criados mas vieram de uma coisa só...tipo assim, é... como se fosse, meio que tipo uma, que nem a gente faz uma, não sei, não é árvore genealógica, mas, tipo assim, da impressão que é uma coisa, mas tem diferentes tipos de dança que traz alguma semelhança entre outras, então, dá impressão que todas vieram de uma coisa só.(Fala de um dos estudantes da turma do $7^{\circ} \mathrm{Ano}, 2018$ ).

Compreendemos as significações como encruzilhadas atravessadas pelas performatividades, em que os caminhos são possibilidades e não certezas. Pressupõe-se uma coexistência de diferentes rumos, os cruzos. Com base na perspectiva da encruzilhada, sob um olhar como potência de mundo, podemos asseverar que ela está diretamente relacionada às culturas de síncope. Para Simas e Rufino (2018, p. 19), “a síncope é a arte de dizer quando não se diz e não dizer quando se está dizendo”. Capoeira, samba, jongo e demais práticas culturais de síncope anunciam possibilidades de educação, batendo tambor, dando pirueta, gingando, sambando, praticando estripulias, ampliando as rasuras da universalidade do cânone ocidental. Diante disso, como possibilidade para transgredir, dobramos a próxima esquina.

\section{Segunda esquina: frestas e cruzos}

A partir das performatividades, as/os estudantes apresentaram suas potências de vida. Exu enuncia-se enquanto potência para sentir, fazer, pensar, inventar e encantar o mundo, no qual "passado, presente e futuro não passam de abstrações" (RUFINO, 2019, p. 25). Em cada "transgressão" das gestualidades, uma fronteira se apresenta; cada intersecção ressalta a 
possibilidade de outros caminhos ou de reinvenção, as quais se introduzem nas frestas deixadas pelos saberes coloniais.

Rufino (2019) concebe a encruzilhada como símbolo pluriversal que atravessa qualquer conhecimento que se reivindica como único. São esses saberes de frestas que se cruzam e ressaltam zonas fronteiriças de tempo/espaço em atravessamentos múltiplos das experiências das/os estudantes, provisórias e inacabadas. Diferentemente do que se propõe na lógica ocidental/colonial, um caminho não anula o outro, visto que se cruzam, se atravessam, esculhambam a linearidade dos caminhos únicos. Seus entroncamentos escancaram as possibilidades de fronteiras e saberes. É a potência de Exu anunciada nas encruzilhadas.

Nesse contexto, o pensamento decolonial emerge para além de uma ação política e epistemológica, pois se compromete com as transformações e transgressões dos limites da colonialidade/modernidade, configurando-se como um empreendimento da América Latina, mais contundente no debate pós-colonial. Rufino (2018) explica que a perspectiva decolonial não é meramente um processo de descolonização, mas sim constante e continuada transgressão, bem como resiliência frente aos padrões de ser/saber/poder do colonialismo.

No decorrer da tematização, buscamos ampliar os conhecimentos sobre as danças tematizadas para compreender os contextos históricos, políticos e sociais em que surgiram e se transformaram, bem como suas gestualidades. Para tanto, convidamos o produtor cultural de bailes black e líder da Equipe Águia Black, Douglas $\mathrm{Dx}^{1}$, para conversar sobre a organização dos bailes e, principalmente, contar suas histórias com o samba-rock.

[...] as visitas de representantes das práticas corporais nas escolas contribuíram na produção de significações distintas. Além disso, tal dispositivo, típico das atividades de ampliação, viabilizou o confronto do discurso do colonizador com a voz do colonizado, do opressor com a do oprimido, do estabelecido e detentor de privilégios com o marginalizado e subjugado. Essas atividades, desde que bem articuladas com a desconstrução e problematização que caracterizam as situações didáticas de aprofundamento, podem ajudar os estudantes a perceberem as relações de poder que influenciam seus olhares sobre o objeto de ensino. (NEVES, 2018, p. 138).

Além das formas de dançar, a participação de Douglas Dx ajudou os/as integrantes do $7^{\circ}$ ano a pensarem o samba-rock de outras maneiras. O mesmo aconteceu com a turma do $8^{\circ}$ ano, durante a tematização do jongo, quando recebemos, na escola, o mestre Jefinho de Tamandaré, membro de uma tradicional família jongueira da cidade de Guaratinguetá (SP).

Os tambores, os pontos, as saias, os giros anunciaram o jongo e como ele é produzido pelos jongueiros, tal como as/os estudantes tinham visto nos vídeos extraídos da internet. Todavia,

${ }^{1}$ Pai de um estudante da escola. 
também acessaram o jongo nas falas do mestre, cujas histórias contadas confundiram (intencionalmente?) os fatos narrados com a própria trajetória do jongo.

Apesar dos relatos do convidado, as/os estudantes apresentaram a forma como o jongo estava sendo produzido nas aulas, o que contrariava a regra vocalizada de "um homem e uma mulher". Homem com homem ou mulher com mulher divergiam da ocorrência social do jongo, não seriam vistos com "bons olhos". Essas outras possibilidades apresentadas pelas/os estudantes não negavam o “jongo de verdade”, mas anunciavam o borramento do que se entende por homem e mulher. A Educação Física culturalmente orientada toma essa situação didática como ressignificação, ou seja, uma apropriação do tema cultural, dado que as/os estudantes também "elaboram outras formas de conhecimento sobre as práticas corporais estudadas, a sociedade que as acolhe e os grupos culturais que as produzem e reproduzem” (NEIRA, 2016b, p. 43).

Vale ressaltar que a participação do mestre Jefinho foi de suma importância ao viabilizar o acesso aos pontos de jongo e fazer circular as representações de alguém, cuja história de vida está profundamente marcada pela prática corporal tematizada. Algo semelhante aconteceu quando houve a visita pedagógica, realizada à Casa de Cultura Fazenda Roseira, em Campinas (SP), uma localidade ocupada pela comunidade Jongo Dito Ribeiro. As turmas jogaram mancala, participaram de uma oficina de percussão, ouviram histórias e conheceram elementos das mitologias africana e afro-brasileira. Também puderam vivenciar uma roda de jongo e conversar sobre a dança produzida na comunidade, o que propiciou a ampliação das representações sobre a manifestação, pois essa comunidade jongueira é liderada e coordenada por mulheres. Logo, as turmas acessaram narrativas distintas daquelas com as quais tinham interagido na escola.

Além das atividades já citadas, as/os estudantes conheceram o centro de referência do jongo do Sudeste, entrevistaram a jongueira mais velha da comunidade, a Dona Maria Ribeiro, vivenciaram a percussão e, no final das atividades, participaram de uma roda de jongo, conduzida por Bianca Ribeiro, neta do Sr. Benedito Ribeiro, que nomeia a comunidade. A turma participou dançando, enquanto Bianca cantava os pontos e explicava o funcionamento do jongo. Aos poucos, as/os estudantes foram vencendo a timidez, tanto para dançar quanto para conversar sobre o jongo com as/os jongueiras/os.

As colocações de Bianca ajudaram a problematizar as relações de gênero e sexualidade, suscitando discussões acaloradas entre as/os estudantes. Todavia, é importante ressalvar que os aspectos relacionados a quem dança com quem ainda predominam nas comunidades jongueiras. Isso foi apresentado como alternativa à utilização da saia e da "não-saia", pelas/os estudantes, de maneira que significa, como tudo que é mobilizado nessa prática, a saber, as metáforas apresentadas 
no jongo, as possibilidades de cruzos, borramentos e atuação - visto que as significações das/os estudantes ocuparam os espaços e desencadearam possibilidades para novas frestas, lançadas na encruzilhada, pois, tudo o que é lançado lá, é também modificado. Nessa perspectiva, qualquer "verdade" logo se transforma em dúvida, potencializando a abertura de outros caminhos, o que nos fez dobrar a terceira esquina.

\section{Terceira esquina: as encruzilhadas como possibilidades e exu como epistemologia}

Ao propor a pedagogia das encruzilhadas, Rufino (2019) anuncia as peripécias, princípios e potências de Exu como epistemologia, o que seria inviável sem os conhecimentos das culturas da diáspora africana, acessados nos diálogos interculturais entre múltiplos saberes. Em concordância com o autor, alertamos que uma educação que rejeita Exu é, portanto, uma educação sem mobilidade, uma educação que não produz mudança, encantamentos e possibilidades, por isso, a importância de pensar uma pedagogia a partir das frestas, no devir, no vir a ser. Entrecruzando as possibilidades de uma epistemologia exuística, recorremos ao conceito de desobediência epistêmica:

A opção descolonial é epistêmica, ou seja, ela se desvincula dos fundamentos genuínos dos conceitos ocidentais e da acumulação de conhecimento. Por desvinculamento epistêmico não quero dizer abandono ou ignorância do que já foi institucionalizado por todo o planeta (MIGNOLO, 2008, p. 290).

A opção do autor é desnudar a identidade escondida sob a pretensão de teorias democráticas universais que, ao mesmo tempo, constroem identidades racializadas pela hegemonia das categorias de pensamento, histórias e experiências do Ocidente. Isso posto, nossa opção é parcial, nada neutra, pois nos orientamos pela desobediência epistêmica, por uma epistemologia exuística ou qualquer episteme que anuncie possibilidades ao invés de certezas.

Reforçando os pressupostos do currículo cultural, na direção de favorecer a enunciação dos saberes discentes (SANTOS JÚNIOR, 2020), as tematizações caminharam nas encruzilhadas por saberes e possibilidades. Ao vivenciarem o samba-rock, as/os estudantes não se mostraram relutantes ao dançar com a/o colega, seja menino ou menina. Essas transgressões, potencializadas por Exu, podem ter sido uma resposta não dada; pode ser que, ao não dizerem nada, disseram muito; ao produzirem danças em duplas, casais, trios ou quartetos, encontraram alternativas para que essas questões não fossem postas.

Isso tudo propicia uma reflexão sobre as configurações apresentadas pelas/os estudantes, visto que anunciaram resistências em relação às discussões que poderiam permear o marcador 
gênero. De certo, isso aconteceu por desejarem não problematizar as relações de gênero, pois foram absorvidos pelas africanidades que perpassam as danças tematizadas.

Do ponto de vista das africanidades:

[...] estudar História e Cultura Afro-brasileira e Africana é também um gesto político, questionador de paradigmas eurocêntricos que costumeiramente marginalizam, desqualificam, negam as contribuições dos africanos para a humanidade. Estudar história e cultura dos povos africanos exige dos professores e estudantes, negros e não negros, aprender a identificar, criticar, desconstruir distorções, omissões, avaliações baseadas em preconceitos, construir novas significações. (SILVA, 2001, p. 45).

A autora também alerta para a necessidade de se combater, também, nossos próprios preconceitos, bem como os gestos de discriminação fortemente enraizados, a fim de superar a ignorância em relação à história e cultura das/os brasileiras/os descendentes de africanas/os. Mesmo que não exista efetivamente uma compreensão de atitudes racistas, ainda assim, somos influenciados pela estrutura na qual as escolas estão inseridas, portanto, "as instituições são racistas porque a sociedade é racista" (ALMEIDA, 2019, p. 47).

Urge a necessidade de reconstruir o discurso pedagógico, no sentido de que a escola venha a participar do processo de resistência dos grupos e classes postos à margem, bem como para contribuir com a afirmação da sua identidade e da sua cidadania. Afinal,

Engana-se quem pensa que a desigualdade, o preconceito ou a injustiça social interessam a alguém. Todos os grupos presentes nas instituições escolares precisam se unir na luta comum pelo fortalecimento da democracia. Uma pedagogia que ajuda a entender a produção das diferenças e apreciar os princípios da equidade não constrói consensos, pois prefere a noção de solidariedade, conceito bem mais inclusivo e transformador. (NEIRA, 2020, p. 835).

Ao entrecruzarmos o currículo cultural de Educação Física e a pedagogia das encruzilhadas, entre artistagens, dinamismos, mobilidades, transgressões, batalhas, jogos, dribles, rasuras, sucateios, ressignificações e estripulias, praticadas nas frestas, surgem múltiplas formas de invenção da vida cotidiana, em meio a Exu como um princípio dinâmico que compreende uma complexa tessitura de práticas e formas.

As análises indicam ter sido possível aos/as estudantes atuar nas frestas produzidas durante a tematização. Com suas significações, metaforicamente, anunciaram a saia e a "não-saia" como texto cultural produzido pelo jongo do $8^{\circ}$ ano; também, ao dançarem de casais, duplas, trios, entre outros; ao dançarem o samba-rock, apontaram para outras possibilidades de ser e de sincopar os conhecimentos anunciados no decorrer de toda a tematização. 
Ao colocar em ação o currículo cultural, atua-se nas frestas, nos cruzos, em síncope; as significações das/os estudantes indicam aproximações do rolê epistemológico e da metáfora da capoeira, uma vez que:

$\mathrm{Na}$ marcação binária que entoa a rítmica do mundo colonial emerge um terceiro tempo, um vazio ressaltado no intervalo entre os dois tons. A síncope, o vazio, campo do imprevisível e, por isso, das possibilidades, há de ser preenchida pelos poderes do corpo. Eis que nasce a ginga, produção de saber do corpo e suporte para um infinito repertório gestual de esquivas, negaças, golpes e rolês. O conceito de rolê epistemológico inspira-se nas sabedorias da capoeira para propor ações de desvio e avanço. Imprime, nesse sentido, a lógica do jogo. Os rolês caçam tempos/espaços para a prática das virações, rola-se de um lado para o outro, finge que vai, mas não vai e aí se dá o bote, eis que o cruzo acontece. (RUFINO, 2019, p. 3).

A capoeira, aqui utilizada com sua flexibilidade improvisadora e resistência aos métodos de ensino e treinamento positivistas, não é só uma manifestação lúdica, é também a forma de enfocar a vida. O capoeirista no seu improviso, atua tanto individualmente, como em harmonia com o seu adversário e o cosmos. É a sua individualidade que catalisa a tensão criativa do grupo, que canta e batuca mais forte, estimulando-o a realizar movimentos novos e nunca imaginados. Quando a "metáfora da capoeira" se introduz como princípio curricular, tanto os estudantes afrodescendentes quanto os pertencentes a outros grupos étnicos inserem-se nos modos africanos de ver e ser (NEIRA, 2007, p. 198).

Exu configura-se como potência dialógica, sendo o não é, nem o eu, nem o outro; ele comporta em si o eu e o outro, além de toda a possibilidade de encontro/conflito/diálogo entre eles.

\section{Considerações finais}

O estudo realizado amplia as conclusões alcançadas por Martins (2019), Oliveira Junior (2017), Araújo e Neira (2014), Neira (2016a) e Neves (2018), ao estabelecer um diálogo com as africanidades anunciadas por Silva (2001), manifestadas na potencialização da presença de Exu como possibilidade de compreensão das significações não lineares. Ao analisarmos os registros das situações didáticas, inicialmente, observamos a resistência, não compreendida como recusa, mas como estranhamento para as possibilidades anunciadas no início da tematização das danças, uma vez que estavam compartilhando, no mesmo patamar, danças de saberes eurocêntricos, estadunidenses e vivenciadas por grupos sociais historicamente marginalizados.

Nesse sentido, a presente pesquisa endossa a importância de favorecer a enunciação dos saberes discentes, apontada por Santos Júnior (2020), acrescentando a possibilidade de diálogo entre culturas, de convivência e partilha coletiva com o diferente. No decorrer da tematização, as/os estudantes tiveram a possibilidade de acessar conhecimentos outros sobre as danças e seus participantes, fazendo circular representações que, inferimos, geraram a produção de significados 
distintos daqueles inicialmente anunciados. Suspeitamos que as atividades propostas tenham proporiconado o borramento dos significados anteriores sobre as práticas corporais e as relações étnico-raciais que sustentam esses conhecimentos.

Uma vez produzidos os significados, o não dito pode dizer além do que é possível expressar. Encontramos, nas performatividades apresentadas pelas/os estudantes, principalmente nos aspectos que se entrecruzaram no jongo, algumas fissuras. Na performatividade, também se anuncia o pensamento de fronteira e a recusa aos universalismos ou formas únicas de se ler a realidade. Pelo não dito, direcionamo-nos para compreender e viver gestualidades, expressões, sentidos e significações produzidas no transcorrer de toda tematização, forjando um assentamento nos processos de ressignificação do ser, suas invenções de territorialidades, saberes e identidades.

Nesse sentido, a encruzilhada anuncia-se como um símbolo pluriversal que atravessa qualquer conhecimento, reivindicado como único, reforçando o pensamento de fronteira e anunciando saberes de frestas, atravessadas por múltiplas experiências, provisórias e inacabadas. Exu emerge como potência capaz de produzir esses atravessamentos a partir da desobediência epistêmica que cria condições para produzir outras significações.

\section{Referências}

ALMEIDA, S. L. Racismo estrutural. São Paulo: Sueli Carneiro; Pólen, 2019.

ARAUJO, L.; NEIRA, M. G. O currículo da Educação Física em ação: análise do processo de significação das práticas corporais por parte dos sujeitos. Iniciação, v. 4, p. 1-17, 2014.

COSTA, M. V. Estudos Culturais - para além das fronteiras disciplinares. In: COSTA, M. V. (Org.). Estudos culturais em educação: mídia, arquitetura, brinquedo, biologia, literatura, cinema... Porto Alegre: Editora da UFRGS, p. 13-36, 2000.

HALL, S. Cultura e representação. Rio de Janeiro: PUC-Rio/Apicuri, 2016.

HALL, S. Identidade cultural na pós-modernidade. Rio de Janeiro: DP \& A, 2006

LISBOA FILHO, F. F.; MACHADO, A. Comunicação e cultura: reflexões sobre a análise cultural como método de pesquisa. XVI Congresso de Ciências da Comunicação na Região Sul, 2015, Joinville/SC. Anais. Joinvile: Intercom, 2015. p. 1 - 15.

MARTINS, J. C. J. Educação Física, currículo cultural e educaşão de jovens e adultos: novas possibilidades. 2019. 381 f. Dissertação (Mestrado em Educação) - Universidade de São Paulo. Faculdade de Educação. São Paulo, SP, 2019.

MIGNOLO, W. Histórias locais/projetos globais: colonialidade, saberes subalternos e pensamento liminar. Belo Horizonte, MG: Editora UFMG, 2013. 
MIGNOLO, W. Desobediência epistêmica: a opção descolonial e o significado de identidade em política. Cadernos de Letras da UFF - Dossiê: Literatura, língua e identidade, no 34, p. 287-324, 2008.

MIGNOLO, W. Histórias locais/projetos globais: colonialidade, saberes subalternos e pensamento liminar. Belo Horizonte: Editora UFMG, 2003.

MORAES, A. L. C. A análise cultural. In: 24 Encontro da Compós, 2015. Anais... Brasília, 2015. Disponível em: http://www.compos.org.br/biblioteca/compos-2015-4df33669-bb034c83-92ab62fbe023bb30_2825.pdf Acesso em 23 de outubro de 2019.

MÜLLER, A. A avaliação no currículo cultural da Educação Física: o papel do registro na reorientação das rotas. 2016. 158f. Dissertação (Mestrado em Educação) - Universidade de São Paulo, Faculdade de Educação, São Paulo, 2016.

NEIRA, M. G. Ensino de Educação Física. São Paulo: Thomson Learning, 2007.

NEIRA, M. G. Currículo de Educação Física e o posicionamento dos sujeitos. Revista Contemporânea de Educaşão, Rio de Janeiro, v. 11, n. 22, p. 115-131, ago./dez. 2016a.

NEIRA, M. G. Os procedimentos didáticos do currículo cultural da Educação Física. In:. NEIRA, M. G.; NUNES, M. L. F. (Org.). Educação Física cultural: escritas sobre a prática. Curitiba: CRV, 2016b.

NEIRA, M. G. Educaşão Física cultural: inspiração e prática pedagógica. $2^{\mathrm{a}}$ Ed. Jundiaí, SP: Paco, 2019.

NEIRA, M. G. Os conteúdos no currículo cultural da Educação Física e a valorização das diferenças: análises da prática pedagógica. Revista e-Curriculum, São Paulo, v. 18, n.2, p. 827-846 abr./jun. 2020.

NEVES, M. R. O currículo cultural de Educaşão Física em ação: efeitos nas representações culturais dos estudantes sobre as práticas corporais e seus representantes. 2018. 198f. Dissertação (Mestrado em Educação). Universidade de São Paulo. Faculdade de Educação. São Paulo, São Paulo, 2018.

OLIVEIRA JÚNIOR, J. L. Significações sobre o currículo cultural da Educaşão Física: cenas de uma escola municipal paulistana. 2017. 156f. Dissertação (mestrado). Universidade de São Paulo. Faculdade de Educação. São Paulo, SP, 2017.

PARAÍSO, M. A. Metodologias de pesquisa pós-crítica em educação e currículo: trajetórias, pressupostos, procedimentos e estratégias analíticas. In: MEYER, D. E.; PARAISO, M. A. (Orgs.). Metodologias de pesquisas pós-críticas em educação. $2^{\mathrm{a}}$ ed. Belo Horizonte: Mazza, 2014.

QUIJANO, Anibal. Colonialidade do poder, eurocentrismo e América Latina. In: LANDER, Edgardo. A colonialidade do saber: eurocentrismo e ciências sociais. Perspectivas latino-americanas. Coleccion Sur Sur, CLACSO, Ciudad Autónoma de Buenos Aires, Argentina.Setembro, 2005.

REIS, R. Educação Física cultural e africanidades: entre decolonialidades, Exu e encruzilhadas. 2021. 173 f. Dissertação (Mestrado em Educação) - Faculdade de Educação, Universidade de São Paulo, São Paulo, 2021. 
RUFINO, L. Pedagogia das Encruqilhadas. Rio de Janeiro: Mórula Editorial, 2019

RUFINO, L. Pedagogia das Encruzilhadas. Revista Periferia, v.10, n.1, p. 71 - 88, Jan./Jun. 2018.

SANTOS JÚNIOR, F. N. Subvertendo as colonialidades: o currículo cultural de educação Física e a enunciação dos saberes discentes. 2020. 184f. Dissertação (Mestrado em Educação) Universidade de São Paulo. Faculdade de Educação. São Paulo, 2020.

SILVA, P. B. G. Aprendizagem e ensino das africanidades brasileiras. In: MUNANGA, K. (Org.). Superando o racismo na escola. Brasília: Ministério da Educação/Secretaria de Educação Fundamental, 2001. p. 151-168.

SIMAS, L. A. S.; RUFINO, L. Fogo no mato: a ciência encantada das macumbas. Rio de Janeiro: Mórula, 2018.

WORTMANN, M. L. C. Análises culturais - um modo de lidar com histórias que interessam à educação. In: COSTA, Marisa Vorraber. (Org.). Caminhos investigativos II: outros modos de pensar e fazer pesquisa em educação. Rio de Janeiro: Lamparina, 2002. p. 71-90. 